\title{
Overcoming Stigma of Human Immunodeficiency Virus Infected Patients: Breaching the Myths
}

\author{
${ }^{1}$ Deepak Nagpal, ${ }^{2}$ Lulu Sherif, ${ }^{3}$ Manpreet S Nanda
}

\begin{abstract}
India has the third highest number of estimated people living with human immunodeficiency virus (HIV) in the world. The current moral panic about HIV/acquired immune deficiency syndrome (AIDS) and the theories of deviance that go with it are not a new phenomenon. People expect dental students to know all about HIVIAIDS, but many experience the same fear and ignorance as the public. There is a need to cultivate non judgmental attitude towards the care of people infected with HIVIAIDS. This requires systematic and sensitive educational program. Recent trends have emphasized the use of interprofessional education (IPE) as a very effective tool to overcome such barriers in delivering optimal health care to these patients. The present article reflects the current scenario of the patients living with HIV and the stigma associated with it. We attempt to propose an IPE module to overcome the same.
\end{abstract}

Keywords: Human immunodeficiency virus, Interprofessional education, Stigma.

How to cite this article: Nagpal D, Sherif L, Nanda MS. Overcoming Stigma of Human Immunodeficiency Virus Infected Patients: Breaching the Myths. J Contemp Dent 2018;8(3):135136.

Source of support: Nil

Conflict of interest: None

\section{INTRODUCTION}

It is more than three decades now, and we still find people living with HIV (PLWHIV) facing a lot of stigma and discrimination within society and to their dismay from health care professionals too. The reasons for this discrimination are quite varied but most commonly due to the lack of awareness and ignorance on the part of the healthcare professional about the epidemiology of the disease. The current scenario in most of our dental institutes is that we work in silos, not interacting or collaborating with expert's knowledgeable about dreaded diseases like HIV. All healthcare workers, especially direct caregivers like physicians, surgeons, dentists,

\footnotetext{
${ }^{1}$ Professor and HOD, ${ }^{2}$ Associate Professor, ${ }^{3}$ Professor

${ }^{1}$ Department of Oral Pathology \& Microbiology, D.Y. Patil Dental School, Lohegaon, Pune, Maharashtra, India

2Department of Anesthesiology, Father Muller Medical College, Mangaluru, Karnataka, India

${ }^{3}$ Department of ENT, Maharishi Markandeshwar Medical College and Hospital, Solan, Himachal Pradesh, India

Corresponding Author: Deepak Nagpal, Professor and HOD D.Y. Patil Dental School, Lohegaon, Pune, Maharashtra, India, e-mail: deepaknagpal2013@gmail.com
}

nurses, and technicians are at risk for occupationally acquired HIV infections due to the increased chance of exposure to blood and other body fluids of patients. The current trend of moral panic about AIDS and the theories of deviance that go with it are not a new phenomenon. People expect dental professionals to know all about HIV/ AIDS, but many experience the same fear and ignorance as the public and hence avoid delivering treatment to these patients. This forces the PLWHIV visiting dental clinics from disclosing their status, thereby creating a greater risk especially for young inexperienced dental students.

\section{CURRENT TRENDS}

New treatment modules (highly active antiretroviral therapy) have increased the lifespan for these afflicted patients, and HIV positivity is presently considered as a chronic manageable disease in medical practice. Increased lifespan leads to increased frequency of such patients visiting the dental clinics. Very few PLWHIV honestly disclose their status. To add on to the woes of these patients, we dental professionals find ourselves incompetent to deliver routine procedures such as root canal treatment, implants or disimpaction in a prompt manner (Fig. 1). Studies have shown that if proper training in managing HIV patients is provided, there is a positive attitude in dental professionals and students to treat such patients. Unfortunately, no such training modules are currently incorporated in the curricula for increasing the competencies in managing patients with $\mathrm{HIV} /$ Hepatitis in dental practice. Hence there is a need

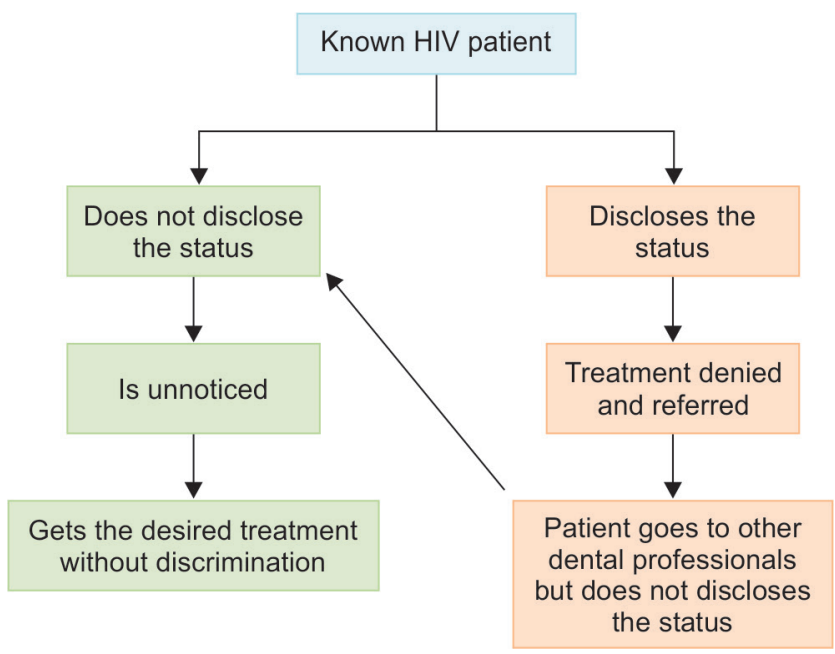

Fig. 1: Current trends of patients visiting dental clinics 


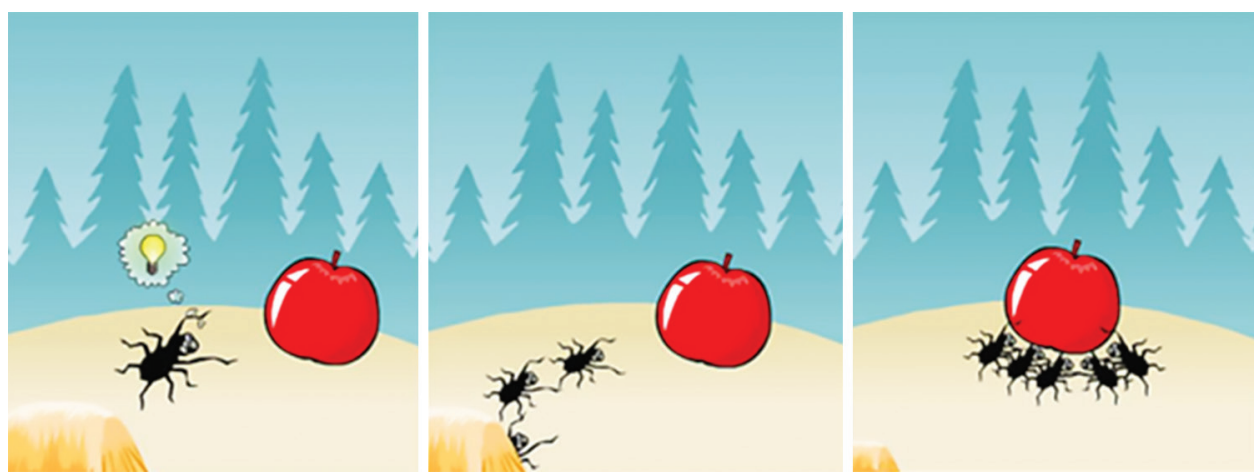

Fig. 2: Just like the ants in this picture, it makes sense that when health care providers work together as a team, challenges can be addressed better and patient care will improve

Table 1: Proposed interprofessional training module

\begin{tabular}{|c|c|c|}
\hline $\begin{array}{l}\text { Sr } \\
\text { No }\end{array}$ & $\begin{array}{l}\text { Interprofessional } \\
\text { team area }\end{array}$ & Role \\
\hline 1. & $\begin{array}{l}\text { Medical subject } \\
\text { expert }\end{array}$ & $\begin{array}{l}\text { Myths and fears, Universal safety } \\
\text { precautions, Post-exposure } \\
\text { prophylaxis }\end{array}$ \\
\hline 2. & $\begin{array}{l}\text { Dental subject } \\
\text { expert }\end{array}$ & $\begin{array}{l}\text { Safe techniques, Universal } \\
\text { precautions, PPE }\end{array}$ \\
\hline 3. & Counselor & Counseling doctors and patients \\
\hline 4. & NGO & Gate to patient care and wellbeing \\
\hline 5. & $\begin{array}{l}\text { Stress } \\
\text { Management } \\
\text { expert }\end{array}$ & $\begin{array}{l}\text { To counter stress associated with } \\
\text { the disease }\end{array}$ \\
\hline 6. & Medico-legal expert & An important part of the module \\
\hline 7. & Media & $\begin{array}{l}\text { Help promote education and make } \\
\text { patients more acceptable in society }\end{array}$ \\
\hline 8. & $\begin{array}{l}\text { Communication } \\
\text { skills expert }\end{array}$ & $\begin{array}{l}\text { A core area of all health care } \\
\text { professionals }\end{array}$ \\
\hline
\end{tabular}

to cultivate a nonjudgmental attitude towards the care of people infected with HIV/AIDS. This requires systematic and sensitive educational programmes which can overcome the gaps in our current dental teaching curriculum. Recent trends have emphasized the use of Interprofessional education as a very effective tool to overcome such barriers in delivering optimal health care to these patients. Interprofessional education is defined as a process by which a group of students (or workers) from health-related occupations, with different educational backgrounds, learn together during certain periods of their education. ${ }^{1,2}$ Interprofessional approaches to patient care are believed to have the potential for improving professional relationships, increasing efficiency, and coordination, and ultimately enhancing patient and health outcomes. ${ }^{1,3}$ After understanding the current needs, an interprofessional training module as enlisted in Table 1 can be a useful strategy to overcome the stigma.

According to the National Strategic Plan (NSP) for HIV/AIDS, by 2020, the focus of the national programme should be on achieving the following fast-track targets: ${ }^{4}$

- $75 \%$ reduction in new HIV infections

- 90-90-90: 90\% of those who are HIV positive in the country know their status, $90 \%$ of those who know their status are on treatment and $90 \%$ of those who are on treatment experience effective viral load suppression
Table 2: A simple guideline in managing HIV patients in dental clinics

\begin{tabular}{ll}
\hline CD4 Count & Treatment protocol \\
\hline $750>$ & $\begin{array}{l}\text { Routine patient like any other following universal } \\
\text { safety procedure }\end{array}$ \\
$500-750$ & $\begin{array}{l}\text { Basic antibiotic coverage as given by CDC } \\
\text { guidelines and following universal safety } \\
\text { procedure }\end{array}$ \\
$250-500$ & $\begin{array}{l}\text { Under broad antibiotic coverage and with medical } \\
\text { clearance from the expert } \\
\text { Should not be treated in a routine dental OPD but to } \\
\text { be hospitalized and under strict medical supervision }\end{array}$ \\
\end{tabular}

- Elimination of mother-to-child transmission of HIV and Syphilis

Table 2 gives a useful guideline to follow in dental clinics for patients with HIV.

\section{Elimination of Stigma and Discrimination}

But the report does not describe any strategies to achieve the elimination of stigma and discrimination. Hence a need to develop and implement the proposed IPE module could bring us closer to achieving this change. Figure 2 is a simple example of team work, that when we health care providers work together as team challenges can be better addressed and patient care will improve.

I always believe that "a small change can bring a huge difference". It is now high time we come together and work to overcome the barrier of stigma and discrimination towards PLWHIV/AIDS.

\section{REFERENCES}

1. D'Eon M. A blueprint for interprofessional learning. Journal of Interprofessional Care. 2005 May 1;19(sup1):49-59.

2. D'Eon M, Proctor P, Cassidy J, McKee N, Trinder K. Evaluation of an interprofessional problem-based learning module on care of persons living with HIV/AIDS. Journal of Research in Interprofessional Practice and Education. 2010 Aug 13; 1(2).

3. Rogers TC, Zaninovic P, Urankar YR, Natto ZS, Turner RL, Toledo GA, et al. An innovative HIV training program for dental students. Journal of Dental Education. 2011 Nov 1;75(11):1426-1433.

4. National Strategic Plan for HIV/AIDS and STI 2017-2024, December 1, 2017; National AIDS Control Organisation Ministry of Health and Family Welfare Government of India. 